\title{
Systems for the management of respiratory disease in primary care - an international series: South Africa
}

\author{
*Eric Bateman ${ }^{a}$, Charles Feldman ${ }^{b}$, Robert Mashc, Lara Fairalla , Rene Englisha, \\ Anamika Jithoo ${ }^{\text {a }}$ \\ a Division of Pulmonology, Department of Medicine, University of Cape Town, and University of Cape Town Lung Institute, Cape Town, \\ South Africa \\ ${ }^{\mathrm{b}}$ Department of Internal Medicine, Witwatersrand University, Johannesburg, South Africa \\ c Department of Family Medicine and Primary Care, Stellenbosch University, Cape Town, Western Cape, South Africa
}

Received 13th December 2008; accepted 22nd December 2008; online 27th January 2009

\begin{abstract}
Introduction: Progress to democracy in South Africa in 1994 was followed by the adoption of a primary health care approach with free access for all. State health facilities serve $80 \%$ of the population, and a private sector comprising general practitioners, specialists and private hospitals, serves the remainder.

National policies and models: There are national prescribing guidelines for common diseases, and these specify the medicines on the Essential Drugs List that are available at primary care facilities for respiratory diseases including asthma, COPD, pneumonia and tuberculosis.

Epidemiology: Asthma prevalence is average among children (13\%) but morbidity is high. COPD rates are high owing to concurrent risk factors of smoking (in both men and women), occupational exposures, biomass fuel use and previous lung infections including tuberculosis. Tuberculosis and HIV are rampant, and together with pneumococcal co-infection account for considerable mortality.

Access to care: Primary care facilities are within reach of most communities, but major barriers to care include loss of income, waiting times in clinics, cost of transportation, and inconvenient hours.

Facilities available: The country is divided into districts each served by a hospital, several community health centres and many fixed or mobile clinics. The latter provide predominantly nurse-led care by nurse practitioners with additional qualifications. Some clinics and most community health centres are served by doctors. Referrals are made to secondary and tertiary hospitals served by specialists.

Future: Innovations to address staff shortages include the creation of the specialty of family medicine for physicians and development of the clinical associate who is trained to perform a limited clinical role, as well as in-service on-site training of nurses through programmes of integrated care for infectious and chronic diseases. There is an urgent need to address low staff morale and medical migration resulting from a decade of poor leadership and AIDS denialism.

Conclusions: The structures and policies for primary care in South Africa provide some grounds for optimism that services may begin to match the promise of quality care for all, but the burden of disease and resource constraints - particularly in terms of qualified personnel - mitigate against an early delivery of this promise.

(c) 2009 General Practice Airways Group. All rights reserved.

E Bateman et al. Prim Care Resp J 2009; 18(2): 69-75.

doi:10.3132/pcrj.2009.00009
\end{abstract}

Keywords epidemiology, nurse, primary care, asthma, chronic, COPD, management, South Africa, facilities, systems, funding, national policy, respiratory disease, guideline

\footnotetext{
* Corresponding author: Professor Eric Bateman, Division of Pulmonology, University of Cape Town, Department of Medicine, PO Box 34560, Groote Schuur, Cape Town, Western Cape, South Africa 7937. Tel: +27 214066901 Fax: +27 214066902 E-mail: eric.bateman@uct.ac.za
} 


\section{Contents}

Background

\section{Background}

This paper on the current provision of primary care services for patients with respiratory disease in South Africa, is the fourth in a planned series of international reviews. In keeping with the aims and objectives of the Primary Care Respiratory Journal, the editors commissioned this series of papers to enable clinicians and health service managers to compare and learn from different systems of primary care management for patients with respiratory disease around the world. Each of the papers in the series will follow a similar format, and will include information on national policy and models, epidemiology, access to care, facilities available, and future developments. By summarising and comparing how different countries provide primary care for patients with respiratory disease we hope to stimulate debate and inform the future development of policies aimed at improving the care worldwide for people with respiratory disease.

\section{Introduction}

The pattern of diseases in South Africa shows some features of epidemiologic transition from infectious disease to diseases of modern living, but with some unique differences.' The Apartheid dispensation, which entrenched opportunity and privilege for a minority, resulted in a bimodal epidemiological picture in that diseases of affluence were juxtaposed with infectious, occupational and poverty-related diseases. The political changes of 1994 were accompanied by health reform and relative economic growth which provided the prospect of improving health for the majority. However, this has been all but annulled by the HIV epidemic and its impact upon the prevalence of tuberculosis (TB). This twin epidemic, coupled with AIDS denialism demonstrated by national leaders, has resulted in a burden from these diseases that is stretching resources to the limit and impacting upon the quality of care that is offered for other health needs, including chronic respiratory diseases.

Nevertheless, the developments in policy and the structuring of health services over the past two decades can be expected to bear fruit in due course. This report describes these changes, the pattern and management of respiratory diseases seen in primary care, and current attempts to improve the quality of care.

\section{National policy and the organisation of health services}

Currently $8 \%$ of gross domestic product (GDP) is spent on health, but more than half of this amount is channelled into medical insurance schemes that serve the contributors and their dependents who constitute less than $20 \%$ of the population. ${ }^{2}$

Therefore, it is apparent that the proportion of GDP committed to the health needs of the majority remains unacceptably low. In order to fund new priorities in primary care, government funds have (over the last decade) been systematically diverted from the previously favoured academic and tertiary centres to the expanding network of primary care clinics in both rural and urban areas. This has brought access to free medical services within the reach of a majority of citizens in the context of a district-based management framework. ${ }^{3,4}$ More than 700 new primary care facilities have been built, bringing the total number of clinics to 4500 , serving a population of approximately 35 million. These facilities are staffed largely by nurse practitioners with limited support from doctors. Since 1996, primary care services have been offered free to all citizens, but, at 2.3 visits per capita per year, use of these facilities remains well below the national target of between 3 and 3.5 visits per year. ${ }^{5}$

Under the District Health System the entire country is subdivided into contiguous geographical districts, each district offering both facility and community-based services. Facilitybased services include the district hospital, community health centres and clinics. Fixed and mobile clinics are the front line for first contact nurse-led primary care services. Community health centres $(\mathrm{CHC})$ are found in larger towns and urban areas and offer a broader range of health workers including full time doctors and pharmacists, and have emergency units, radiology services and ambulatory care. In larger $\mathrm{CHCs}$, separate services may be offered for patients with TB or HIV, and even for selected diseases such as asthma and diabetes. The district hospital is run by generalist medical officers with wards for adults, children and maternity services. ${ }^{4}$

Community-based services for chronic care are limited and are predominantly provided by non-governmental organisations and charities; some focus on specific diseases such as home-based care for HIV or community-based directly 
Table 1. Medications listed in the national EDL for the treatment of respiratory diseases in primary care. ${ }^{6}$

- Amoxycillin

- Erythromycin

- Doxycycline

- Benzyl penicillin

- TB medication (Isoniazid, Ethambutol, Rifampicin, Pyrazinamide, Streptomycin)

- Co-trimoxazole

- Salbutamol pMDI and nebulizer solution

- Budesonide pMDI

- Slow release theophylline

- Ipratropium bromide pMDI and nebulizer solution

- Prednisolone

- Hydrocortisone (injectable)

- Adrenaline

- Influenza vaccine

observed treatment (DOT) for TB. However, in some provinces support groups for chronic diseases are being developed by the health departments to alleviate pressure on facilities and encourage self-care amongst patients with asthma, COPD and other chronic diseases. ${ }^{4}$

South Africa currently has an essential drug list (EDL) that specifies the medications that are available at each level of the health system together with national guidelines for their use in each disease. Both have been developed through a process of consultation with primary care physicians, specialists, and other interest groups, but are broadly based on recommendations provided by the World Health Organisation. Medications currently provided free of charge in primary care facilities for the treatment of respiratory diseases are listed in Table $1 .{ }^{6}$

The district health services usually refer to regional (level 2) hospitals where the basic specialties such as internal medicine, surgery, paediatrics and obstetrics and gynaecology are available. Acute illness that cannot be managed at the district hospital is referred to level 2 as well as referrals for specialist outpatient consultation. Each regional hospital refers to tertiary (level 3) hospitals, situated in the major urban areas, where sub-specialities, such as pulmonology, are offered. ${ }^{4}$

A major limitation to the provision of good quality primary care is a shortage of trained staff, particularly of nurses and doctors. This shortage has arisen through a confluence of factors: poor planning that resulted in too few nurses being trained; staff migration to other countries; and poor staff morale as a result of the lack of provision of anti-retroviral therapy (ART) (rendering staff unable to offer more than palliative care for patients with HIV) coupled with the risks associated with handling HIV and TB patients. The need for doctors in underserved areas has been partly alleviated by a 1-year compulsory Community Service program, and more recently by the introduction of a 4-month intern rotation in Family Medicine, Primary Care and Mental Health. Although inexperienced, the former has increased the numbers of doctors in rural areas. In rural areas doctors are often foreignborn from countries in Africa and elsewhere. The SA Health Review of 2003 estimated that the availability of doctors in the public sector varied from 32 per 100,000 in the Western Cape to a low of 11 per 100,000 in North West province. The availability of nurses varied from 131 per 100,000 in the Free State to 89 per 100,000 in North West with a national average of 107 per $100,000 .^{5}$

In 2007 the Health Professions Council of South Africa (HPCSA) created the new specialty of Family Medicine, intended to provide well trained generalists who could improve the range and quality of services at the district hospital and in primary care. In addition, approval has been given to introduce a new cadre of mid-level health worker, the clinical associate, who will be trained to support the family physician in district hospitals in specific procedures and emergency services.

A further category of health personnel with a special role in primary care is the clinical nurse practitioner. Clinical nurse practitioners receive post-graduate training that enables them to make diagnoses and treat common conditions in primary care, but the course requirements for this training, with respect to duration and content has not yet been standardised across the country. Furthermore there is some evidence to suggest that these courses have not led to improvements in the quality of care provided.?

The private health services in South Africa are well developed and are the primary providers of health care for about $20 \%$ of the population; they are also available at the patient's expense to those usually served by the public sector. Primary care is provided by general practitioners (GPs), the majority of whom practice in group practices or clinics of varying sizes, some of which are in health centres providing radiology, pathology and other services. Private medical insurance schemes have recently been obliged to offer basic services for a range of chronic diseases including asthma and COPD to those patients accepted as paying members of the scheme.

\section{Epidemiology of respiratory diseases}

The task facing primary care facilities in South Africa may be judged from surveys of the reasons why patients seek health care, and from prevalence studies of respiratory diseases in the community. Studies using the International Classification of Primary Care have confirmed that cough is the commonest complaint in primary care and that respiratory conditions 
account for eight of the top 10 diagnoses encountered in this setting (including upper respiratory tract infection (URTI), tonsillitis, otitis media, pneumonia, acute bronchitis, asthma and influenza). Among adults, nine of the top 25 diagnoses are also respiratory problems (URTI, acute bronchitis, influenza, pneumonia, tonsillitis, TB, asthma, otitis media and sinusitis). ${ }^{8}$

The prevalence of respiratory diseases has been assessed more accurately in community-based epidemiologic studies. The prevalence of symptoms of chronic bronchitis was found to be lower than that reported from many European countries. ${ }^{9}$ However, as in other developing countries, the association with cigarette smoking was less pronounced owing to contributions from exposures to dust and fumes in industry, ${ }^{9,10,11}$ indoor pollution from biomass fuelled fires, ${ }^{12,13}$ previous $\mathrm{TB},{ }^{14}$ and childhood pneumonia, as significant additional risk factors. ${ }^{9}$ In addition, the association of these symptoms with relatively little evidence of airflow obstruction (based on measurement of peak expiratory flow) suggested that such symptoms were more of an irritant nature, rather than reflecting a high prevalence of COPD. In contrast to these results, much higher rates of both chronic bronchitis (9.2\% in women and $12.6 \%$ in men over age 40 years) and of COPD have been reported in a low-middle-income working community of mixed ethnicity in Cape Town. ${ }^{15}$ In this study the prevalence of current smoking was $57 \%$ in adult males and $42 \%$ in females. This contrasts with national averages of $42 \%$ among men and $23 \%$ among women 16 In this community the prevalence of GOLD stage II COPD among both men and women was higher than that reported from 12 other sites globally that used the same methodology. ${ }^{17}$ Additional observations in this community were the association of chronic bronchitis with regular cannabis use, and of COPD with a history of previous pulmonary tb. ${ }^{10}$ These results highlight the need to consider local "hot spots" where risk factors combine to cause very high levels of disease.

The prevalence of asthma has not been reliably estimated for the whole of South Africa, but is reported as the eighth leading contributor to the burden of disease in South Africa ahead of diabetes and cardiovascular diseases. ${ }^{18}$ Only in the Western Cape province has the standardised ISAAC methodology been used to assess asthma prevalence among children. In these studies the prevalence of 'ever wheezing' among 9-13 year-old children in Cape Town was 13.2\%, similar to the global average. ${ }^{19}$ However, when stratified for socioeconomic (SE) status (using a social deprivation index), asthma was more common in those with higher SE status, but symptoms were more frequent, and ICU admissions and asthma deaths more common, in those from poorer suburbs. ${ }^{19,20}$ It is not clear whether these figures apply to the rest of South Africa since the Western Cape province differs from the rest of the country in having a Mediterranean climate, unique vegetation, and a high prevalence of house dust mite. Moreover, several studies comparing the prevalence of asthma in rural and urban Africans have confirmed lower levels of asthma in rural populations. ${ }^{21}$

As might be expected in a transitional disease profile, and especially with the high prevalence of HIV infections, lower respiratory tract infections, including pneumonia, are a leading cause of death and years of life lost (YLL) in South Africa. ${ }^{18,22,23}$ In 1996 lower respiratory tract infections accounted for $4.0 \%$ of deaths in males (the seventh leading cause of death) and $4.8 \%$ in females (the fifth leading cause of death) and $3.9 \%$ and $5.4 \%$ of YLL for males and females, respectively. ${ }^{22}$ More recent data from Statistics South Africa (2007) indicates that in 2005, "Influenza and Pneumonia" was the third leading cause of death overall, accounting for $7.71 \%$ of deaths. Most of these cases were described in more detail as "Pneumonia: organism unspecified". ${ }^{23}$

Perhaps most alarming of the respiratory conditions in South Africa is tuberculosis. The World Health Organization (WHO) publication on global TB control (2008) reported that in 2006 the incidence of TB (all cases/100,000 population/year) was estimated to be 940 and the prevalence (all cases/100,000 population) 998.24 Between 2005 and 2006 there was an estimated $1.6 \%$ increase in the incidence rate, and South Africa ranked fourth in Africa based on the estimated number of incident cases of TB (all forms). ${ }^{24}$ Data from Statistics South Africa (2007) indicated that TB was the leading cause of death in South Africa in 2005, accounting for $12.5 \%$ of deaths (a total of 73,903 deaths), an increase from $7 \%$ (22,071 deaths) in 1997. ${ }^{23}$ As expected, much of this increased mortality is in patients co-infected with the HIV. In the report on 2006 only one third had been tested for HIV, and $44 \%$ of new cases were found to be sero-positive for $\mathrm{HIV}^{23}$ These statistics must be interpreted in the light of the fact that ART was only introduced in 2004, and most deaths would have been in untreated patients. However, they serve to illustrate the considerable burden that these two diseases present for the health services.

Several studies in sub-Saharan Africa among HIV-infected patients presenting with a lower respiratory tract infection have confirmed that TB is the principal cause of AIDs-related deaths, accounting for up to $30 \%$ of deaths, and that community-acquired pneumonia is the second. ${ }^{25}$ This finding has been confirmed in a study at a teaching hospital in KwaZulu Natal in which $81.4 \%$ of 430 consecutive patients with pneumonia were found to be HIV-seropositive and in those in whom a pathogen was found, 39.6\% had TB and $34.5 \%$ Streptococcus pneumoniae. ${ }^{26}$

Successful treatment rates for TB in South Africa have reached $70 \%$, but this is still well below the target of $85 \%$ set 
by the WHO. ${ }^{24}$ The recent publicity surrounding the emergence of multi-drug resistant and extremely drugresistant TB strains in South Africa has highlighted the importance of an effective service that achieves high cure rates in drug-sensitive cases. ${ }^{27}$ To achieve this adherence is critical, and although reasons for poor adherence are numerous, recent surveys in South Africa have confirmed that good relationships with the nurses in the primary care facility and access to care in rural areas are important issues that need to be addressed. ${ }^{28}$ Programmes such as PALSA PLUS ${ }^{29}$ are beginning to focus on training staff in a more people-centred rather than disease-centred manner, in line with the approach recommended in the 2008 WHO World Health Report entitled Primary Health Care: Now More Than Ever. ${ }^{30}$

\section{Access to care and innovation in primary healthcare}

Although public sector primary care is free, access to care is limited by other financial and structural barriers. For example, low-paid workers may not afford to take time off to attend clinics that only function during working hours. Although in urban areas some clinics are open throughout the night, most are strictly day clinics and might close their doors to those patients who arrive halfway through the morning if the waiting room is full. By contrast, access to private GPs in their rooms is generally not subject to delays for those who can afford this route, or who have medical insurance. The distance to, travel time, and/or cost of transportation to, clinics in rural areas are also important deterrents to attendance.

Patients returning for ART, TB medications, vaccinations and other chronic diseases (such as asthma and COPD) may be seen in a specialised service within larger health centres and in this way avoid the general queues. While this may improve continuity it can lead to fragmented care with little attention being paid to the other needs of patients. In the HIV era it is common for patients to have several complaints that require diagnostic review and treatment or referral. This consideration has been the motivation for ensuring that all clinic staff, and particularly nurses, receive training in all the service areas and conditions treated at the clinic, if only so that recognition and referral is ensured.

This type of integrated approach to the management of diseases in primary care is being encouraged by the WHO and by disease-specific programmes such as the STOP TB Programme $^{31}$ and the Global Alliance Against Chronic Respiratory Diseases (GARD) as a means of strengthening health services and improving the care of patients with chronic diseases. ${ }^{32}$ In South Africa, this has been investigated and introduced in some provinces under the name PALSA PLUS - Practical Approach to Lung Health in South Africa. ${ }^{29}$ PALSA PLUS was first developed and tested in the Free State province and involved the development of a syndromic, integrated guideline for the diagnosis and care of patients with priority respiratory diseases including TB, asthma and $\mathrm{COPD}^{33}$ and an educational outreach programme to enable nurse practitioners to use the guideline to manage these diseases. ${ }^{34}$ The guideline was validated by comparing the nurse diagnosis and treatment to specialist diagnosis and treatment, confirming its performance. ${ }^{35}$ A second study, a pragmatic randomised controlled trial in 40 rural primary care clinics in the Free State province, examined its impact in changing clinical practice and certain process outcomes. Favourable outcomes included increased TB case detection (OR 1.72; $95 \% \mathrm{Cl} 1.04$ - 2.85), increased prescription of inhaled corticosteroids in the intervention group (OR 1.9; $95 \% \mathrm{Cl} 1.14-3.18$ ), and more appropriate referral of patients with severe disease to the next level of care. ${ }^{36}$ Since then the programme has been expanded to include the treatment of sexually transmitted diseases, HIVIAIDS and ART, and additional chronic diseases, and it has been endorsed by the National Department of Health for implementation in other provinces.

The PALSA PLUS programme forms the basis for the daily practice of nurses in primary care. Training is offered on-site by a trained supervisor, herself/himself a nurse with primary care experience, and nurses are encouraged and empowered to manage uncomplicated respiratory diseases. ${ }^{29}$ In the case of asthma and COPD, this may involve initial treatment with a bronchodilator and, in the case of asthma, a low dose of inhaled corticosteroid for one month, while referral to a doctor for confirmation of diagnosis is planned. They also treat acute exacerbations of asthma and COPD, sinusitis, middle ear infections and lower respiratory tract infections, counsel patients after obtaining consent, test for HIV infection, collect sputum in TB suspects, and initiate TB treatment in uncomplicated smear-positive cases. Other tasks include counselling for smoking cessation and vaccination for influenza. They also monitor and supervise TB chemotherapy and patients on ART with special responsibility to recognise adverse effects of drugs, defaulting and the development of concurrent medical or social problems. PALSA PLUS does not prescribe measurement of airflow limitation, since the diagnostic accuracy of syndromic diagnosis for initial treatment was found to be satisfactory for this level of care and the addition of airflow measurements in all nurse-led clinics impractical. However, spirometric assessment by primary care physicians is encouraged to confirm asthma and to assess the severity of COPD.

In contrast to the PALSA PLUS which is an innovation designed to improve integrated care within the state-funded primary care clinics, local professional societies have collaborated to develop and implement a country-wide 
disease-specific intervention for asthma that involves all health sectors in South Africa. Termed the Asthma Guidelines Implementation Project (AGIP), the purpose of the project is to achieve optimal care for patients with asthma by disseminating and implementing the new national asthma guideline..$^{37,38}$ The methodology includes outcome mapping techniques to ensure participation of all sectors (termed boundary partners) and the setting of goals and monitoring of progress of each. The plan involves multi-faceted interventions targeted at patients, public and private primary care providers (nurses, doctors, pharmacists), the Department of Health, medical aid schemes, pharmaceutical companies, university and training bodies, and hospital-based specialists in pulmonology, allergy and paediatics. The project is being piloted in the Western Cape province. An initial audit of asthma care in the province revealed that despite inhaled steroids being available and prescribed, only $31 \%$ of patients were well controlled, one out of every six visits was for an exacerbation, and one out of every five patients had been hospitalised in the previous year. Although facilities were well equipped to manage acute asthma, health workers often failed to distinguish asthma from COPD, and rarely assessed the level of control (11.5\% of visits) or inhaler technique (14\% of patients). Patients were poorly educated about asthma and there were no resources (individual or group educational materials, placebo inhalers) to support better education. In $60 \%$ of facilities there was no-one with responsibility for organising chronic care. ${ }^{39}$ The overall impression was that a more comprehensive approach to chronic care was required that went beyond the provision of medication. Results in the relatively well-resourced Western Cape are likely to be as good as or better than other provinces.

\section{Further developments and conclusions}

The challenges presented by respiratory disease in South Africa are formidable, and, owing to the HIV epidemic, greater than any previously faced. This challenge demands a concerted response from the authorities, health departments, health practitioners and society. After a disastrous start - in which the need to address one of the principle factors, the AIDS epidemic, was overlooked by the authorities - there are several encouraging signs of progress: a primary care network; free access to care and essential drugs; a functioning referral network; the development of categories of health personnel to strengthen service delivery; innovative approaches in clinical practice and education; and sufficient economic growth to ensure a sustained source of funding for health. Areas of concern are: the overall low level of spending on health; medical and nurse migration to other countries; the slow response to human resource shortages; and the emergence of new forms of drug resistant TB and HIV infection.

In a country of almost 50 million people, improvements and innovations take time to implement, and many lives will be lost before even approved provisions such as ART and the PALSA PLUS programme are fully implemented. However, times of greatest need produce the most rewarding opportunities for primary care practitioners who gain satisfaction from making a difference.

\section{Conflict of interest declaration}

None to declare.

\section{References}

1. Omran AR. The epidemiologic transition. A theory of the Epidemiology of population change. 1971. Bull World Health Organ 2001;79(2):161-70.

2. Blecher M, Thomas S. Health Care Financing. In: Ijumba P, Day C, Ntuli A (ed). South Africa Health Review 2003/04. Durban: Health Systems Trust. 269-288. http://www.hst.org.za/uploads/files/chap20_03.pdf.

3. National Department of Health Strategic Plan 2004/5 - 2006/7. Pretoria: Department of Health 2004. URL:http://www.doh.gov.za/docs/misc/stratplan/

4. McCoyD, Engelbrecht B. Establishing the District Health System. Durban: Health Systems Trust. 1999. http://www.hst.org.za/uploads/files/bsdhs.pdf

5. Padarath A, Ntuli A, Berthiaume L. Human Resources. In: Ijumba P, Day C, Ntuli A (ed). South Africa Health Review 2003/04. Durban: Health Systems Trust. 299-315.

6. South African National Department of Health. 1998. Standard Treatment Guidelines and Essential Drugs List for South Africa (2nd ed). Pretoria: South African National Department of Health.

7. Louwagie GMC, Bachmann MO, Reid M. Formal clinical primary health care training. Does it make a difference? Curationis 2002;25(4):32-37.

8. Mfenyana K and Mash B. A different context of care. In Mash B (ed). Handbook of Family Medicine, 2006, Cape Town: Oxford University Press.

9. Ehrlich R, White N, Norman R, et al. Predictors of chronic bronchitis in South African adults. Int J Tuberc Lung Dis 2004;8:369-76.

10. Ehrlich R, Jithoo A. Chronic Respiratory Diseases in South Africa. In: Jean Fourie, Norman Temple, Krisela Steyn (Eds). Chronic Diseases of Lifestyle in South Africa: Review of Research 1995-2005. MRC Technical Report. May 2006.

11. Hnizdo E. Health risks among white South African goldminers - dust, smoking and chronic obstructive pulmonary disease. S Afr Med J 1992;81:512-17.

12. Grobbelaar J, Bateman ED. Hut lung - a domestically acquired pneumoconiosis of mixed aetiology in rural women. Thorax 1991;46:334-40. doi:10.1136/ thx.46.5.334

13. Van Hoorn C, Nel R, Terblanche P. Indoor air pollution from coal and wood use in South Africa: an overview. Energy for Sustainable Development III:1996;3840. http://dx.doi.org/10.1016/S0973-0826(08)60179-9

14. Churchyard GJ, Hnizdo E, White N. Pulmonary Tuberculosis in Relation to Lung Function Loss. In: Safety in Mines Research Advisory Committee (SIMRAC) Research Report: Health 617. 2001. Johannesburg: SIMRAC.

15. Jithoo A, White NW, Beyers N, Irusen E, van Lill S, Bateman ED. High prevalence, under-diagnosis and under-treatment of chronic bronchitis in South Africa - an example of differing risk factors in developing countries. Int J Tuberc Lung Dis 2005;9:\$283.

16. South African National Department of Health, Medical Research Council, Demographic and Health Surveys Macro International Inc. 1998. South African Demographic and Health Survey 1998 - Preliminary Report. Pretoria: South African Department of Health. Available from: http://www.mrc.ac.za/ bod/dhsfin1.pdf.

17. Buist AS, McBurnie MA, Vollmer WM, et al. International variation in the 
prevalence of COPD (the BOLD Study): A population-based prevalence study. Lancet 2007;370:741-50. http://dx.doi.org/10.1016/S0140-6736(07)61377-4

18. Bradshaw D, Groenewald $P$, Laubscher $R$, et al. Initial burden of disease estimates for South Africa, 2000. S Afr Med J 2003;93(9):682-8.

19. Poyser MA, Nelson $H$, Ehrlich RI, et al. Socioeconomic deprivation and asthma prevalence and severity in young adolescents. Eur Respir J 2002;19(5):892-8. http://dx.doi.org/10.1183/09031936.02.00238402

20. Zar HJ, Stickells D, Toerien A, Wilson D, Klein M, Bateman ED. Changes in fatal and near-fatal asthma in an urban area of South Africa from 1980 - 1997. Eur Respir J 2001;18:33-7.

21. Van Niekerk CH. Prevalence of asthma. Clinical Allergy 1979;9:319-24.

22. Bradshaw $D$, Schneider $M$, Dorrington $R$, et al. South African cause-of-death profile in transition-1996 and future trends. S Afr Med J 2002;92(8):618-23.

23. Statistics South Africa. Mortality and causes of death in South Africa, 2005; Findings from death notification (Statistical Release P0309.3). www.statssa.gov.za.

24. World Health Organization. Global Tuberculosis Control: Surveillance, Planning, Financing. WHO Report 2008.

25. Murray JF. Pulmonary complications of HIV-1 infection among adults living in sub-Saharan Africa. Int J Tuberc Lung Dis 2005;9(8):826-35.

26. Nyamande K, Lalloo UG, John M. TB presenting as community-acquired pneumonia in a setting of high TB incidence and high HIV prevalence. Int $J$ Tuberc Lung Dis 2007;11:1308-13.

27. Andrews JR, Shah NS, Gandhi N, Moll T, Friedland G, Tugela Ferry Care and Research (TF CARES) Collaboration. Multidrug-resistant and extensively drugresisitant tuberculosis: implications for the HIV epidemic and antiretroviral therapy rollout in South Africa. J Infect Dis 2007;196(Suppl 3):S482-90. doi:10.1086/521121

28. Dick J, Lombard C. Shared vision - a health education project designed to enhance adherence to anti-tuberculosis treatment. Int J Tuberc Lung Dis 1997; 1:181-6.

29. Stein J, Lewin S, Fairall L, et al. Building capacity for antiretroviral delivery in South Africa: A qualitative evaluation of the PALSA PLUS nurse training programme. BMC Health Serv Res 2008,8:240. [Epub ahead of print] PMID:19017394. http://dx.doi.org/10.1186/1472-6963-8-240
30. World Health Report 2008: Primary Health Care more now than ever. Geneva: World Health Organisation. 2008. Available from http://www.who.int/whr/ 2008/whr08_en.pdf.

31. World Health Organization. 2005. Practical Approach to Lung Health (PAL): a primary healthcare strategy for the integrated management of respiratory conditions in people five years of age and over. WHO/HTM/TB/2005.351. Geneva: World Health Organization. Available from: http://whqlibdoc.who.int/ hq/2005/WHO_HTM_TB_2005.351.pdf.

32. Global surveillance, prevention and control of chronic respiratory diseases; a comprehensive approach. Geneva. World Health Organisation, 2007; p84-85. http://www.who.int/fard/publication/GARD_Manual/en/index.html.

33. English RG, Bateman ED, Zwarenstein MF, et al. Development of a South African integrated syndromic respiratory disease guideline for primary care. Prim Care Resp J 2008;17:156-63. http://dx.doi.org/10.3132/pcrj.2008.00044

34. Bheekie A, Buskens I, Allen S, et al. The Practical Approach to Lung Health in South Africa PALSA) intervention: respiratory guideline implementation for nurse trainers. Int Nurs Rev 2006;53:261-8. http://dx.doi.org/10.1111/j.14667657.2006.00520.x

35. English RG, Bachmann M, Bateman ED, et al. Diagnostic accuracy of an integrated respiratory guideline in identifying patients with respiratory symptoms requiring screening for pulmonary tuberculosis: a cross-sectional study. BMC Pulmonary Medicine 2006;6:22. http://dx.doi.org/10.1186/14712466-6-22

36. Fairall LR, Zwarenstein M, Bateman ED, et al. Effect of educational outreach to nurses on tuberculosis case detection and primary care of respiratory illness: pragmatic cluster randomised controlled trial. BMJ 2005;331:750-4. http://dx.doi.org/10.1136/bmj.331.7519.750

37. Working Group South African Thoracic Society. South African Thoracic Society 2007 Guidelines for the management of chronic asthma in adolescents and adults. South African Family Practice 2007;49(5):19-31.

38. Mash R, Ainslie G, Irusen E, Mayers P, Bheekie A. The dissemination and implementation of national asthma guidelines in South Africa: the use of outcome mapping. SA Fam Pract 2007;49:5-8.

39. Mash R, Pather M, Rhode $H$, et al. The quality of asthma care in the Western Cape Province of South Africa. Results of audit at www.pulmonology.co.za

\section{Available online at http://www.thepcrj.org}

